\title{
Preoperative clinical pathway of breast cancer patients: determinants of compliance with EUSOMA quality indicators
}

Delphine Héquet ${ }^{*, 1,2,3}$, Cyrille Huchon ${ }^{2,4}$, Sandrine Baffert ${ }^{5}$, Séverine Alran ${ }^{6}$, Fabien Reyal ${ }^{6,7,8}$, Thuy Nguyen ${ }^{9}$, Alix Combes ${ }^{10}$, Caroline Trichot ${ }^{11}$, Karine Alves ${ }^{12}$, Hélène Berseneff ${ }^{13}$ and Roman Rouzier ${ }^{1,2}$

${ }^{1}$ Department of Surgical Oncology, Institut Curie-Centre René Huguenin, 35 Rue Dailly, 92210 Saint-Cloud, France; ${ }^{2}$ Equipe d'Accueil 7285, Risk and Safety in Clinical Medicine for Women and Perinatal Health, University Versailles-Saint-Quentin, 2 av de la source de la Bièvre, 78180 Montigny-le-Bretonneux, France; ${ }^{3}$ School of Oncology, Paris-Sud University, ED418 Paris, France; ${ }^{4}$ Department of Obstetrics and Gynecology, Hôpital de Poissy-St Germain, 10 Rue du Champ Gaillard, 78300 Poissy, France; ${ }^{5}$ Center of studies and innovations in health, Fondation A. de Rothschild, 25 rue Manin, 75940 Paris, France; ${ }^{6}$ Department of Surgical Oncology, Institut Curie, 26 rue d'Ulm, 75005 Paris, France; ${ }^{7}$ Residual Tumor and Response to Treatment Lab, Translational Research Department, Institut Curie, 75005, Paris, France; ${ }^{8}$ UMR932 Immunity and Cancer, INSERM, Institut Curie, 75005 Paris, France; ${ }^{9}$ Department of Obstetrics and Gynecology, Assistance Publique-Hôpitaux de Paris, Hôpital Louis Mourier, 178 Rue des Renouillers, 92701 Colombes, France; ${ }^{10}$ Department of Obstetrics and Gynecology, Hôpital André Mignot, 177 Rue de Versailles, 78150 Le Chesnay, France; ${ }^{11}$ Department of Obstetrics and Gynecology, Assistance Publique-Hôpitaux de Paris, Hôpital Antoine Béclère, 157 Rue de la Porte de Trivaux, 92140 Clamart, France; ${ }^{12}$ Department of Obstetrics and Gynecology, Hôpital Victor Dupouy, 95107 Argenteuil, France and ${ }^{13}$ Department of Obstetrics and Gynecology, Hôpital René Dubos, 6 Avenue de l'île de France, 95300, Pontoise, France

Background: The European Society of Breast Cancer Specialists (EUSOMA) has defined quality indicators for breast cancer (BC). The aim of this study was to describe the preoperative clinical pathway of breast cancer patients and evaluate the determinants of compliance with EUSOMA quality indicators in the Optisoins01 cohort.

Methods: Optisoins01 is a prospective, multicentric study. Data from operable BC patients were collected, including results from before surgery to 1 year follow-up. Seven preoperative EUSOMA quality indicators were compared with the clinical pathways Optisoins01.

Results: Six hundred and four patients were included. European Society of Breast Cancer Specialists targets were reached for indicator 1 (completeness of clinical and imaging diagnostic work-up), 3 (preoperative definitive diagnosis) and 5 (waiting time). For indicator 8 (multidisciplinary discussion), the minimum standard of $90 \%$ of the patients was reached only in general hospitals and comprehensive cancer centres. Having more than 1 medical examination within the centre was associated with an increased waiting time for surgery, whereas it was reduced by having an outpatient breast biopsy. The comprehensive cancer centre type was the only parameter associated with the other quality indicators.

Conclusions: European Society of Breast Cancer Specialists quality indicators are a useful tool to evaluate care organisations. This study highlights the need for a standardised and coordinated preoperative clinical pathway.

*Correspondence: Dr D Héquet; E-mail: delphine.hequet@gmail.com

Received 9 December 2016; revised 28 March 2017; accepted 3 April 2017; published online 25 April 2017

(C) 2017 Cancer Research UK. All rights reserved 0007-0920/17 
The European Society of Breast Cancer Specialists (EUSOMA) has defined quality indicators in breast cancer (Del Turco et al, 2010). Moreover, EUSOMA has recently listed the requirements of a Breast Centre, defined as 'a place where breast cancer is diagnosed and treated' (Wilson et al, 2013). It is recognised that a quality assurance policy for breast cancer management should be compulsory. Therefore, EUSOMA indicators are a useful tool to evaluate quality of care in routine practice. Some studies have already used several of these indicators to evaluate clinical practice, such as in surgery, chemotherapy or radiation (Kiderlen et al, 2015; van Dam et al, 2015). However, very few data have been published on the quality of preoperative clinical pathways, and most of them concern only surgery waiting time (Cordeiro et al, 2015; Liederbach et al, 2015).

The aim of this study was to describe the preoperative clinical pathway of breast cancer patients and evaluate determinants of compliance with EUSOMA preoperative quality indicators in a prospective, multicentric study.

\section{PATIENTS AND METHODS}

Optisoins01 cohort. This study was conducted on the Optisoins01 cohort, a French, multicentric, prospective study that has already been described (Baffert et al, 2015). Optisoins01 was an observational study conducted with early-stage breast cancer patients from a defined regional health territory covering $35 \%$ of the population of the Ile-de-France region (total population: 11.9 million). The main objective of Optisoins 01 was to identify the main care pathway of early breast cancer patients treated with initial surgery and to evaluate costs from different perspectives (hospital, health insurance). The secondary objectives were to assess quality of care, patient satisfaction, need for supportive care and work reintegration, as well as to evaluate the interactions between health-care providers in and out of the hospital. Eight nonprofit hospitals participated in the study: 4 local hospitals (centre type 1), 3 university hospitals (centre type 2) and 1 comprehensive cancer centre (2 geographical sites, centre type 3 ). All patients that were consecutively managed in the participating centres with histologically confirmed, previously untreated, operable breast cancer were included in the study. Data were collected from patients before surgery, after surgery, after adjuvant therapy and at 1 year follow-up and included in- and outpatient care provided from diagnosis to 1 year follow-up as well as the type of surgery, mode of hospitalisation and adjuvant therapy. In addition, patient satisfaction, sociodemographic data and out-of-pocket data were collected during the entire study period, but these data will not be presented in this analysis. An individual consent by each patient was required for the study. This study was approved by the French National Ethics Committee (CCTIRS Authorisation no. 14.602 and CNIL DR-2014-167).

Data analysed in this study. In the present study, we analysed preoperative data from the first diagnosis examination to the day of surgery. The diagnosis was made following either a screening (imaging) of the national programme or individual imaging from clinical suspicion of breast cancer. In France, the screening programme involves all women aged 50 to 74 years old and consists of a mammogram every 2 years.

EUSOMA preoperative quality indicators. For each indicator, EUSOMA described a 'minimum standard' (MS) for the centre to be a referral breast cancer centre, and also a 'target' $(\mathrm{T})$ to reach to improve quality of care. For some indicators, reaching the MS is mandatory, whereas others are only recommended.

Management and care pathways of the Optisoins01 patients were evaluated by the EUSOMA preoperative quality indicators, related to clinical pathways and care access (Del Turco et al, 2010).
Available data of our cohort allowed us to evaluate the following indicators that relate to the breast cancer pathway and care access:

- Completeness of clinical and imaging diagnostic work-up: The proportion of women with breast cancer who preoperatively underwent mammography, physical examination and ultrasound, MS: 90, T: 95\%.

- Preoperative diagnosis: The proportion of women with breast cancer (invasive or in situ) who had a preoperative definitive diagnosis, MS: 80, T: $90 \%$.

- Waiting time for surgery: The time between the date of the first diagnostic examination within the breast unit and the date of surgery or the start of another treatment within 6 weeks, MS: 75, T: $90 \%$.

- Magnetic resonance imaging (MRI) availability: The proportion of cancer cases examined preoperatively by MRI, MS: 5\%, T: NA.

- Genetic counselling availability (non-mandatory): The proportion of cancer cases referred for genetic counselling, MS: $5 \%$, T:NA.

- Preoperative multidisciplinary discussion: The proportion of cancer patients to be discussed by a multidisciplinary team, MS: 90, T: 99\%.

- The proportion of patients referred for nurse counselling at the time of primary treatment, MS: 85 , T: $95 \%$.

In addition, we explored the use of two more parameters in reference to the requirement of clear written information describing diagnosis and treatment options (Wilson et al, 2013): leaflets on surgery as well as a written individual health-care plans.

Because the determinants of the waiting tile and the determinants of the other quality indicators may be different, we analysed the

\begin{tabular}{|c|c|c|}
\hline & $n /$ median & $\% /$ range \\
\hline Age (years) & 58 & $27-94$ \\
\hline Working patient & 314 & $52 \%$ \\
\hline $\begin{array}{l}\text { Cancer diagnosis } \\
\text { Screening } \\
\text { Imaging } \\
\text { Clinical }\end{array}$ & $\begin{array}{l}210 \\
181 \\
213\end{array}$ & $\begin{array}{l}35 \% \\
30 \% \\
35 \%\end{array}$ \\
\hline $\begin{array}{l}\text { Centre type } \\
\text { General hospital } \\
\text { Teaching hospital } \\
\text { Cancer centre }\end{array}$ & $\begin{array}{c}83 \\
74 \\
447\end{array}$ & $\begin{array}{l}14 \% \\
12 \% \\
74 \%\end{array}$ \\
\hline Distance from residence to care centre $(\mathrm{km})$ & 11.9 & $0-63.4$ \\
\hline $\begin{array}{l}\text { Histological type } \\
\text { In situ } \\
\text { Invasive }\end{array}$ & $\begin{array}{c}60 \\
544\end{array}$ & $\begin{array}{l}10 \% \\
90 \%\end{array}$ \\
\hline $\begin{array}{l}\text { Lymph node involvement } \\
\text { Yes } \\
\text { No } \\
\text { NA }\end{array}$ & $\begin{array}{c}143 \\
424 \\
37\end{array}$ & $\begin{array}{c}24 \% \\
70 \% \\
6 \%\end{array}$ \\
\hline $\begin{array}{l}\text { Breast surgery type } \\
\text { Conservative } \\
\text { Radical }\end{array}$ & $\begin{array}{l}494 \\
110\end{array}$ & $\begin{array}{l}82 \% \\
18 \%\end{array}$ \\
\hline $\begin{array}{l}\text { Axillary node surgery type } \\
\text { Sentinel biopsy } \\
\text { Sentinel biopsy followed by lymph node } \\
\text { dissection } \\
\text { Lymph node dissection } \\
\text { NA }\end{array}$ & $\begin{array}{c}453 \\
39 \\
73 \\
39\end{array}$ & $\begin{array}{c}75 \% \\
6 \% \\
12 \% \\
6 \% \\
\end{array}$ \\
\hline \begin{tabular}{|l|} 
Hospitalisation type \\
Outpatient hospitalisation \\
Conventional hospitalisation \\
\end{tabular} & $\begin{array}{l}363 \\
241 \\
\end{array}$ & $\begin{array}{l}60 \% \\
40 \% \\
\end{array}$ \\
\hline
\end{tabular}


waiting time from the first consultation within the centre to the time of surgery, and separately described the compliance to four quality indicators (preoperative multidisciplinary discussion, written individual health-care plan, leaflets on surgery and preoperative nurse consultation).

Statistical analysis. Analysis of the factors related to compliance with quality indicators was performed with Fisher's exact test or Student's $t$-test. A multivariate analysis was conducted using a logistic regression model. Differences were considered significant at $P<0.05$. All data analyses were performed using $\mathrm{R}$ software (Vienna, Austria) (R Core Team, 2012).

\section{RESULTS}

Population and preoperative clinical pathways. More than 750 patients matched the inclusion criteria and were approached to be enrolled in the study (January-December 2014). A total of 617 patients were included in the Optisoins 01 study and 13 of them dropped out during the follow-up. Data of 604 patients were available for this study. Seventy-four per cent of the patients were managed in a comprehensive cancer centre $(n=447)$. Ninety per cent of the patients $(n=544)$ had invasive breast cancer, and $82 \%$
( $n=494)$ underwent breast-conserving surgery. The majority of the surgical procedures $(60 \%, n=363)$ were performed during outpatient hospitalisation. All the patient and cancer characteristics, surgical procedures and hospitalisation modes are summarised in Table 1.

Almost all patients had an outpatient imaging examination (either mammogram, breast ultrasound or breast magnetic imaging) before being managed within the care centre (96\%, $n=580) ; 35 \%(n=210)$ of these patients underwent the examination in the context of the national screening programme. All patients were first treated by surgery, whereas $20 \%$ had a preoperative consultation with a medical oncologist within the centre $(n=123)$ and $9 \%$ consulted with a radiation oncologist $(n=54)$. Within the centre, $87 \%$ of the patients had a second reading of the outpatient imaging $(n=505)$, and $84 \%(n=425)$ had a new in-patient imaging examination (Figure 1). More than half of the patients had an outpatient breast biopsy $(58 \%, n=352)$, and only $7.6 \%$ of the patients had a second biopsy at the cancer centre in addition to an outpatient biopsy $(n=46)$.

Compliance with EUSOMA indicators. We first analysed seven EUSOMA quality indicators in breast care, which evaluated the preoperative phase (Table 2). Targets were reached for all centre types for indicator 1 (completeness of clinical and imaging

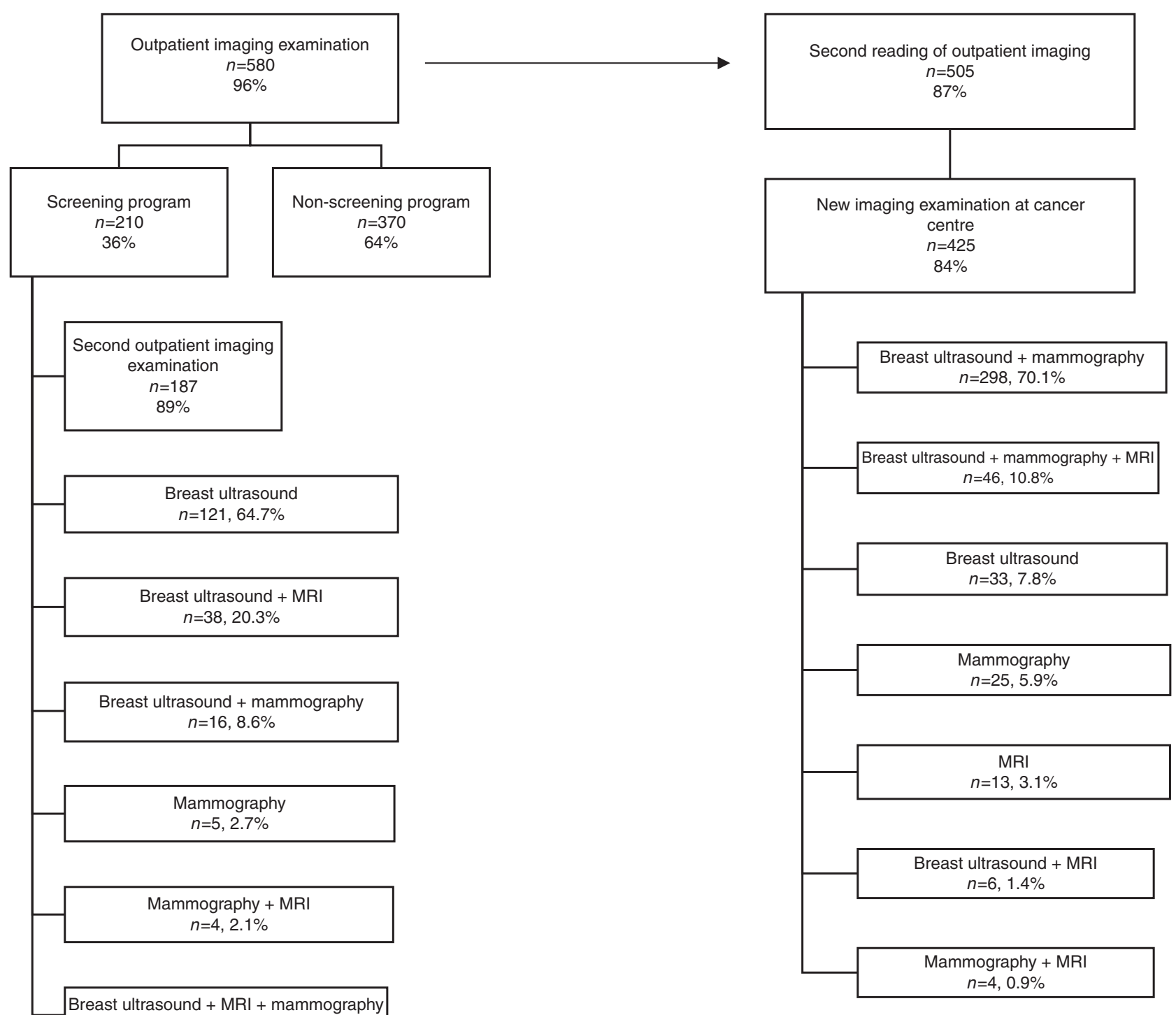

Figure 1. Preoperative imaging examinations. 
diagnostic work-up), indicator 3 (proportion of women with breast cancer who had a preoperative definitive diagnosis) and indicator 5 (waiting time). We considered this last indicator to be the time between the first consultation within the centre and the date of surgery; the median time was 21 days (2-125). Time from the first surgical examination within the centre and surgery is also presented in Figure 2 (median: 17.5 days). The MS was not reached for genetic counselling availability, which is not mandatory but is recommended as a guarantee of access to this service. In contrast, a multidisciplinary discussion is a mandatory indicator, and the MS of $90 \%$ of patients was not reached (87\%). If we look to this indicator in subgroup analysis by centre types, we observed that the MS was reached for centres of types 1 and 3 (99\% and 95\%, respectively) but not for the type 2 centres (35\%). Seventy-four per cent of the patients were preoperatively referred for nurse counselling, which is less than the recommended rate (85\%); this rate was achieved when patients were managed in a comprehensive cancer centre (88\%). Written individual health-care plans and leaflets on surgery were given to the patients in more than $80 \%$ of the cases.

Determinants of compliance with quality indicators. In a univariate analysis, having more than 1 consultation within the centre before surgery was associated with a longer waiting time. As a consequence, when the first medical examination was with a surgeon within the centre, more than $75 \%$ of the patients had a shorter waiting time for surgery. Finally, having the first biopsy outside the centre was associated with a reduced waiting time for surgery (Table 3). In multivariate analysis, two factors were found to be independent factors associated with waiting time. First, patients having more than one medical examination within the centre were less likely to wait fewer than 42 days before surgery (OR: 0.15 ; 95\% CI: $0.06-0.41, P<0.005$ ). Next, patients having an outpatient breast biopsy were more likely to have a waiting time for surgery of fewer than 42 days (OR: 3.89; 95\% CI: 2.06-7.60, $P<0.005)$. In univariate analysis, the factors associated with the four previously described quality indicators were the cancer diagnosis modality, centre type, number of medical and imaging examinations within the centre, place of first biopsy, axillary node surgery type and the hospitalisation modality (Table 4). On the other hand, in the multivariate analysis, the only independent factor associated with these four quality indicators was the comprehensive cancer centre type $(P<0.005)$.

\section{DISCUSSION}

We have presented the first results of a large, prospective, observational study exploring care pathways in early-stage breast cancer. The multicentricity aspect of this study represents the reallife cancer care system, as three different types of care centres that were involved in this study. In France, the National Institute of Cancer has also described the requirements for a centre to manage breast cancer patients (Institut National du Cancer, 2016). In addition to the qualifications of the oncologists, six transversal measures are also required: an adapted information system, multidisciplinary case management meetings, written individual care health plan, good practice guidelines, access to supportive care

\section{Table 2. Compliance with EUSOMA quality indicators}

\begin{tabular}{|c|c|c|c|c|c|c|c|c|}
\hline Indicator & $\begin{array}{l}\text { Level of } \\
\text { evidence }\end{array}$ & $\begin{array}{l}\text { Mandatory/ } \\
\text { recommended }\end{array}$ & $\begin{array}{c}\text { Minimum standard } \\
(\%)\end{array}$ & $\begin{array}{l}\text { Target } \\
(\%)\end{array}$ & $\begin{array}{c}\text { Centre } 1 \\
(\%)\end{array}$ & $\begin{array}{c}\text { Centre } 2 \\
(\%)\end{array}$ & $\begin{array}{c}\text { Centre } 3 \\
(\%)\end{array}$ & $\begin{array}{l}\text { Total } \\
(\%)\end{array}$ \\
\hline 1 & III & $M$ & 90 & 95 & 100 & 100 & 100 & 100 \\
\hline 3 & III & $M$ & 80 & 90 & 100 & 100 & 100 & 100 \\
\hline 5 & IV & $\mathrm{R}$ & 75 & 90 & 93 & 95 & 90 & 91 \\
\hline 6 & IV & $\mathrm{R}$ & 5 & NA & $>5$ & $>5$ & $>5$ & $>5$ \\
\hline 7 & IV & $\mathrm{R}$ & 5 & NA & $<5$ & $<5$ & $>5$ & $<5$ \\
\hline 8 & IV & $M$ & 90 & 99 & 94 & 32 & 95 & 87 \\
\hline 17 & IV & $\mathrm{R}$ & 85 & 95 & 5 & 66 & 88 & 74 \\
\hline
\end{tabular}

Abbreviations: EUSOMA = European Society of Breast Cancer Specialists; MRI = magnetic resonance imaging; NA = not applicable. Indicators (1): Diagnosis One completeness of clinical and imaging diagnostic work-up (proportion of women with breast cancer who preoperatively underwent mammography, ultrasound and physical examination). Three the proportion of women with breast cancer (invasive or in situ) who had a preoperative definitive diagnosis. Five waiting time (time between the date of the first diagnostic examination within the unit and the date of sSix MRI availability. Seven Genetic counselling availability. Surgery and locoregional treatment Eight multidisciplinary discussions (proportion of cancer patients to be discussed). Seventeen the proportion of patients referred for nurse counselling at the time of primary treatment. Centres: Centre 1: General hospital. Centre 2: Teaching hospital. Centre 3: Cancer centre.

A

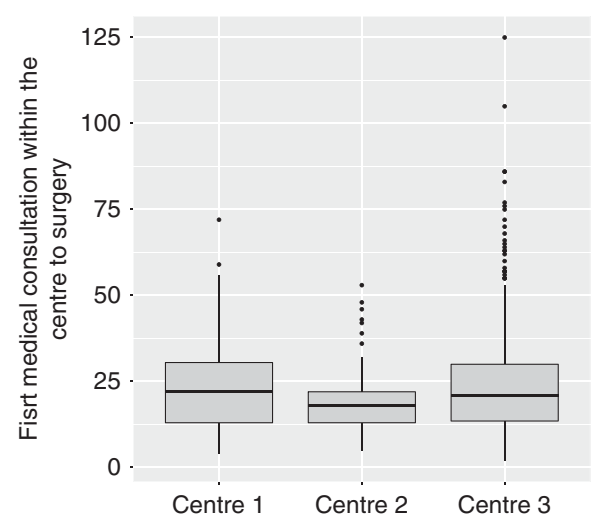

B

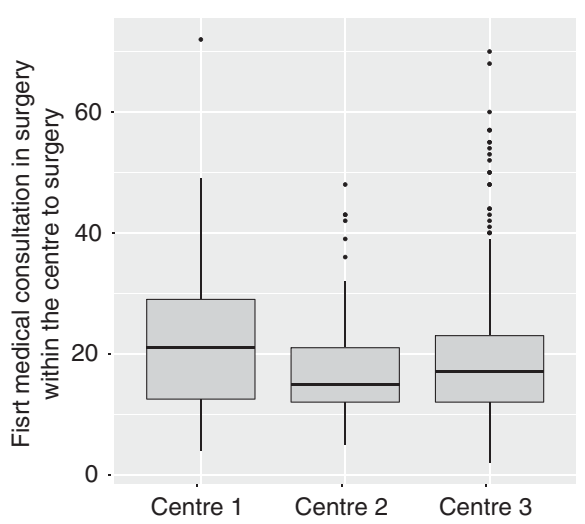

Figure 2. Waiting time for surgery in days. (A) From first medical consultation within the centre. (B) From the first medical consultation in surgery within the centre. 
Table 3. Univariate analysis of the factors associated with waiting time from first medical consultation within the centre to the time of surgery

\begin{tabular}{|c|c|c|c|c|c|}
\hline & \multicolumn{2}{|c|}{$>42$ days, $n=55$} & \multicolumn{2}{|c|}{$<42$ days, $n=549$} & $P$-value \\
\hline \multicolumn{6}{|l|}{ Patient and cancer characteristics } \\
\hline Working patient & 24 & $43.6 \%$ & 290 & $52.8 \%$ & 0.205 \\
\hline Distance to care centre & 9 & $0-51$ & 12 & $0-63$ & 0.951 \\
\hline Cancer diagnosis & & & & & 0.697 \\
\hline Screening & 22 & $40.0 \%$ & 188 & $34.2 \%$ & \\
\hline Centre type & & & & & 0.437 \\
\hline General hospital & 6 & $10.9 \%$ & 77 & $14.0 \%$ & \\
\hline Teaching hospital & 4 & $7.3 \%$ & 70 & $12.8 \%$ & \\
\hline Cancer centre & 45 & $81.8 \%$ & 402 & $73.2 \%$ & \\
\hline Histological type & & & & & 1 \\
\hline In situ & 5 & $9.1 \%$ & 50 & $9.1 \%$ & \\
\hline Surgery & 19 & $34.5 \%$ & 415 & $75.6 \%$ & \\
\hline Others & 36 & $65.5 \%$ & 134 & $24.4 \%$ & \\
\hline$>2$ Imaging examinations ${ }^{a}$ & 41 & $74.5 \%$ & 399 & $72.7 \%$ & 0.874 \\
\hline Place of first imaging ${ }^{a}$ & & & & & 0.525 \\
\hline Outpatient care & 51 & $92.7 \%$ & 513 & $93.4 \%$ & \\
\hline In-patient care & 4 & $7.3 \%$ & 28 & $5.1 \%$ & \\
\hline Magnetic resonance imaging & 7 & $12.7 \%$ & 65 & $11.8 \%$ & 0.828 \\
\hline$>1$ biopsy & 7 & $12.7 \%$ & 70 & $12.8 \%$ & 1 \\
\hline Place of first biopsy & & & & & $<0.005$ \\
\hline Outpatient care & 19 & $34.5 \%$ & 325 & $59.2 \%$ & \\
\hline In-patient care & 34 & $61.8 \%$ & 204 & $37.2 \%$ & \\
\hline NA & 2 & $3.6 \%$ & 20 & $3.6 \%$ & \\
\hline \multicolumn{6}{|l|}{ Planned surgery } \\
\hline \multicolumn{6}{|l|}{ Other quality indicators } \\
\hline Leaflets on surgery & 48 & $87.3 \%$ & 463 & $84.3 \%$ & 0.697 \\
\hline Preoperative nurse consultation & 44 & $80.0 \%$ & 403 & $73.4 \%$ & 0.336 \\
\hline Written individual health care plan & 46 & $83.6 \%$ & 441 & $80.3 \%$ & 0.720 \\
\hline Preoperative multidisciplinary meeting & 52 & $94.5 \%$ & 474 & $86.3 \%$ & 0.093 \\
\hline
\end{tabular}

and access to innovation and clinical studies. However, authorisation to treat breast cancer is given only if a centre manages more than 30 patients a year. All of the centres involved in this study had official authorisation to manage breast cancer patients. Based on EUSOMA requirements, the German Cancer Society and the German Society for Breast Cancer established a certification system in 2003. More than 200 certified centres were therefore evaluated in 2013 (Kowalski et al, 2015). Most of the centres fulfilled the requirements, and the variation between sites decreased. The implementation of a certification system ensures good quality of care. However, evaluation of the practice is critical to maintaining care quality. Therefore, the EUSOMA quality indicators are good tools to evaluate best practices in breast cancer, regardless of the country, and to standardise the quality of care. In this way, compliance with EUSOMA quality indicators has been assayed by age for more than 40000 breast cancers across Europe (Kiderlen et al, 2015); 13 indicators considering treatment were used in this study, whereas diagnosis, staging and follow-up were not evaluated. Only one of the EUSOMA diagnosis indicators was evaluated in another European study (van Dam et al, 2015). Within 22 breast units in Germany, Italy, Switzerland, Austria and Belgium, $86.2 \%$ of the patients managed between 2006 and 2012 had a complete preoperative diagnosis (target 90\%); other indicators evaluated in this study considered only the treatment.

We evaluated diagnosis quality indicators in the present study. Waiting time for treatment is the most explored criterion in the literature. In addition to being a source of anxiety for patients, waiting time for treatment can also reveal inequalities in care access. Therefore, it is a good indicator of health system performance. However, waiting time considered in the literature is very heterogeneous. Several waiting times are described: from first imaging to treatment, from first medical evaluation to 
Table 4. Univariate analysis of the factors associated with four quality indicators ${ }^{a}$

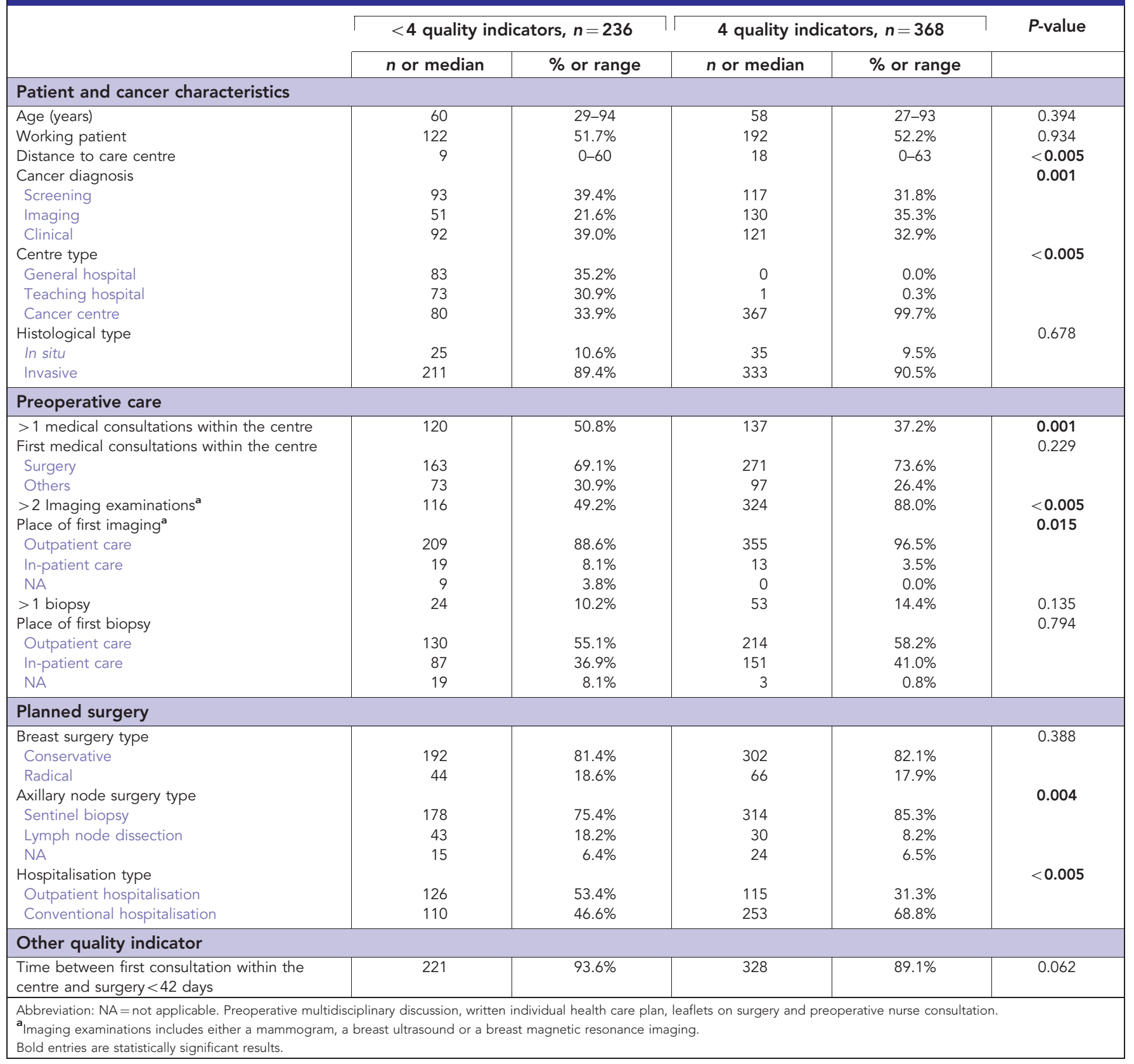

treatment, from definitive diagnosis to treatment and including $v s$ not including working days. Hence, a Canadian retrospective study evaluating more than 60000 patients described a median time from first examination to surgery of 52 days (Cordeiro et al, 2015). In France, the National Cancer Institute described a 23-day median time from diagnosis or the multidisciplinary meeting therapeutic decision and treatment, with important regional disparities (Pourcel et al, 2013). Moreover, which threshold should be considered for each waiting time? Should we consider waiting time in terms of prognosis? Results in the literature about the impact of treatment waiting time on prognosis are controversial, but a recent study suggests an increase in mortality for each 60-day increasing interval: added risk of death due to breast cancer for each 60-day increase in preoperative time to surgery had a subdistribution hazard ratio of $1.26(P=0.03$; Bleicher et al, 2016). Furthermore, patient opinions of an acceptable waiting time should also be considered. More than 7500 Canadian patients were asked whether different waiting times for surgery were acceptable or not. Approximately one-third of the patients considered a waiting time $>4$ weeks to be unacceptable (Sanmartin et al, 2007). On the other hand, in a German study in which the median waiting time for surgery was 14 days, almost all of the patients were satisfied (Arndt et al, 2003). Again, the definitions of waiting time and the threshold were heterogeneous. Therefore, the EUSOMA quality indicators help achieve consistency in the definitions of waiting time and also enable comparisons across countries in addition to national recommendations and practice, even if they do not account for the prehospital phase. In our study, the target was reached for all centre types in terms of waiting time for surgery.

In the Medicare population in the United States, based on the SEER database, the median interval from breast cancer diagnosis to surgery increased from 21 days in 1992 to 32 days in 2005 (Bleicher et al, 2012). This trend, observed in several countries, could be linked to an increasing incidence of breast cancer, partly due to systematic screening. Therefore, it is essential to study the determinants of surgery waiting time. Repetitive imaging or 
preoperative MRI are the most relevant factors influencing waiting time for surgery, with a 7- to 10-day increase in time when MRI is performed (Bleicher et al, 2009; Baliski et al, 2014; Ayrault-Piault et al, 2016). In our cohort, having a preoperative MRI did not impact the waiting times, wherever the patients were managed (comprehensive cancer centre, teaching hospital or general hospital); access to MRI in our study reflects access to MRI in the most populated region of France. In our study, having more than one preoperative medical consultation within the centre increased waiting time significantly. Moreover, waiting time between the first consultation and surgery was shorter when first visiting a surgeon. This suggests the importance of better coordination of the patients after outpatient examinations, which could be partly improved with the help of general practitioners. However, increased waiting times can also result from a better preoperative diagnosis that includes definitive pathological and IHC diagnoses before surgery, multidisciplinary discussions and quality information (several consultations if needed, such as nurse counselling). All of these steps also ensure quality of care (Coates, 1999). Finally, having had one or more medical consultations could also be explained by the cancer type itself: patients who require more than one consultation are usually medically more complex.

Organisation of multidisciplinary care around tumour boards has been identified as an essential element in cancer care by the European Partnership for Action Against Cancer (EPAAC), launched by the European Commission in 2009 (European Partnership Action Against Cancer Consensus Group et al, 2014). Moreover, discussion in multidisciplinary meetings can lead to changes in the recommendations for surgical management in 12 to $52 \%$ of cases (De Leso et al, 2013; Baliski et al, 2014). While some studies have evaluated the barriers and aids to multidisciplinary meeting implementation, very few data are available on how many cancer patients benefit from it. In our study, the overall rate of cases discussed in multidisciplinary boards did not reach EUSOMA requirements. However, when we examined the rates per centre type, we observed that the EUSOMA MS was not achieved only in the teaching hospitals. Moreover, in our multivariate analysis, we found that the only factor associated with the four quality indicators (preoperative multidisciplinary discussion, written individual health-care plan, leaflets on surgery and preoperative nurse consultation) was centre type (comprehensive cancer centre). Indeed, in these centres, which manage bigger volumes, care pathways are standardised. In particular, this type of care organisation includes a systematic preoperative nurse consultation and a structure for written, delivered information (written individual health-care plan, leaflets on surgery). Integrated oncological care pathways are proven to be an effective policy to improve quality of care (van Dam et al, 2013), but there is still a need to extend the implementation of this standardised pathway (van Hoeve et al, 2014). The results of this study will serve as a basis for the debate among physicians of the centres and health officials to improve the quality of care of breast cancer patients.

\section{CONCLUSION}

European Society of Breast Cancer Specialists quality indicators are useful tools to evaluate preoperative quality of care and clinical pathway in breast cancer management. The results of this prospective, multicentric study reveal the impact of the preoperative clinical pathway on waiting time for surgery. Repetitive preoperative medical consultation and imaging examinations increase the waiting time for surgery, which could be minimised with the help of navigation nurses and/or general practitioners. Moreover, compliance with other quality indicators is improved in comprehensive cancer care centres with bigger volumes that offer standardised care pathways. The results of this study are an additional argument for facilitating the implementation of such standardised care pathways in all centres managing breast cancer.

\section{ACKNOWLEDGEMENTS}

This study was supported by a grant from the French National Cancer Institute, dedicated to economic studies of innovative techniques. Delphine Hequet benefitted from a 'Fondation pour la Recherche Medicale' (FDM20140630453) grant to conduct this study.

\section{CONFLICT OF INTEREST}

The authors declare no conflict of interest.

\section{REFERENCES}

Arndt V, Stürmer T, Stegmaier C, Ziegler H, Becker A, Brenner H (2003) Provider delay among patients with breast cancer in Germany: a population-based study. J Clin Oncol 21: 1440-1446.

Ayrault-Piault S, Grosclaude P, Daubisse-Marliac L, Pascal J, Leux C, Fournier E, Tagri AD, Métais M, Lombrail P, Woronoff AS, Molinié F (2016) Are disparities of waiting times for breast cancer care related to socio-economic factors? A regional population-based study (France). Int J Cancer 139: 1983-1993.

Baffert S, Hoang HL, Brédart A, Asselain B, Alran S, Berseneff H, Huchon C, Trichot C, Combes A, Alves K, Koskas M, Nguyen T, Roulot R, Rouzier R, Hequet D (2015) The patient-breast cancer care pathway: how could it be optimized? BMC Cancer 15: 394.

Baliski C, McGahan CE, Liberto CM, Broughton S, Ellard S, Taylor M, Bates J, Lai A (2014) Influence of nurse navigation on wait times for breast cancer care in a Canadian regional cancer center. Am J Surg 207: 686-691, discussion 691-692.

Bleicher RJ, Ciocca RM, Egleston BL, Sesa L, Evers K, Sigurdson ER, Morrow M (2009) Association of routine pretreatment magnetic resonance imaging with time to surgery, mastectomy rate, and margin status. J Am Coll Surg 209: 180-187, quiz 294-295.

Bleicher RJ, Ruth K, Sigurdson ER, Ross E, Wong YN, Patel SA, Boraas M, Topham NS, Egleston BL (2012) Preoperative delays in the US Medicare population with breast cancer. J Clin Oncol 30: 4485-4492.

Bleicher RJ, Ruth K, Sigurdson ER, Beck JR, Ross E, Wong YN, Patel SA, Boraas M, Chang EI, Topham NS, Egleston BL (2016) Time to surgery and breast cancer survival in the United States. JAMA Oncol 2: 330-339.

Coates AS (1999) Breast cancer: delays, dilemmas, and delusions. Lancet 353 : 1112-1113.

Cordeiro E, Dixon M, Coburn N, Holloway CM (2015) A patient-centered approach to wait times in the surgical management of breast cancer in the Province of Ontario. Ann Surg Oncol 22: 2509-2516.

De Leso PB, Coward JI, Letsa I, Schick U, Nandhabalan M, Frentzas S, Gore ME (2013) A study of the decision outcomes and financial costs of multidisciplinary team meetings (MDMs) in oncology. Br J Cancer 109: 2295-2300.

Del Turco MR, Ponti A, Bick U, Biganzoli L, Cserni G, Cutuli B, Decker T, Dietel M, Gentilini O, Kuehn T, Mano MP, Mantellini P, Marotti L, Poortmans P, Rank F, Roe H, Scaffidi E, van der Hage JA, Viale G, Wells C, Welnicka-Jaskiewicz M, Wengstöm Y, Cataliotti L (2010) Quality indicators in breast cancer care. Eur J Cancer 46: 2344-2356.

European Partnership Action Against Cancer Consensus GroupBorras JM, Albreht T, Audisio R, Briers E, Casali P, Esperou H, Grube B, Hamoir M, Henning G, Kelly J, Knox S, Nabal M, Pierotti M, Lombardo C, van Harten W, Poston G, Prades J, Sant M, Travado L, Valentini V, van de Velde C, van den Bogaert S, van den Bulcke M, van Hoof E, van den Neucker I, Wilson R (2014) Policy statement on multidisciplinary cancer care. Eur J Cancer 50: 475-480.

Institut National du Cancer. les autorisations de traitement du cancer. Available at http://www.e-cancer.fr/Professionnels-de-sante/Lorganisation-de-l-offre-de-soins/Traitements-du-cancer-lesetablissements-autorises/Les-autorisations-de-traitement-du-cancer (lasst accessed 20 November 2016). 
Kiderlen M, Ponti A, Tomatis M, Boelens PG, Bastiaannet E, Wilson R, van de Velde CJ, Audisio RA. eusomaDB Working Group (2015) Variations in compliance to quality indicators by age for 41,871 breast cancer patients across Europe: a European Society of Breast Cancer Specialists database analysis. Eur J Cancer 51: 1221-1230.

Kowalski C, Ferencz J, Brucker SY, Kreienberg R, Wesselmann S (2015) Quality of care in breast cancer centers: results of benchmarking by the German Cancer Society and German Society for Breast Diseases. Breast 24: 118-123.

Liederbach E, Sisco M, Wang C, Pesce C, Sharpe S, Winchester DJ, Yao K (2015) Wait times for breast surgical operations, 2003-2011: a report from the National Cancer Data Base. Ann Surg Oncol 22: 899-907.

Pourcel G, Ledesert B, Bousquet PJ, Ferrari C, Viguier J, Buzyn A (2013) Waiting times for cancer care in four most frequent cancers in several French regions in 2011 and 2012. Bull Cancer 100: 1237-1250.

$\mathrm{R}$ Core Team (2012) R: a language and environment for statistical computing. $\mathrm{R}$ Foundation for Statistical Computing, Vienna, Austria; ISBN 3-900051-07-0. Available at: http://www.R-project.org/ [http://lib.stat.cmu.edu/r/CRAN. (last accessed 20 November 2016).

Sanmartin C, Berthelot JM, McIntosh CN (2007) Determinants of unacceptable waiting times for specialized services in Canada. Healthc Policy 2: e140-e154.

van Dam PA, Tomatis M, Marotti L, Heil J, Wilson R, Rosselli Del Turco M, Mayr C, Costa A, Danei M, Denk A, Emons G, Friedrichs K, Harbeck N, Kiechle M, Koheler U, Kuemmel S, Maass N, Marth C, Prové A, Kimmig R, Rageth C, Regolo L, Salehi L, Sarlos D, Singer C, Sohn C,
Staelens G, Tinterri C, Ponti A, eusomaDB Working Group (2015) The effect of EUSOMA certification on quality of breast cancer care. Eur J Surg Oncol 41: 1423-1429.

van Dam PA, Verheyden G, Sugihara A, Trinh XB, Van Der Mussele H, Wuyts H, Verkinderen L, Hauspy J, Vermeulen P, Dirix L (2013) A dynamic clinical pathway for the treatment of patients with early breast cancer is a tool for better cancer care: implementation and prospective analysis between 2002-2010. World J Surg Oncol 11: 70.

van Hoeve J, de Munck L, Otter R, de Vries J, Siesling S (2014) Quality improvement by implementing an integrated oncological care pathway for breast cancer patients. Breast 23: 364-370.

Wilson ARM, Marotti L, Bianchi S, Biganzoli L, Claassen S, Decker T, Frigerio A, Goldhirsch A, Gustafsson EG, Mansel RE, Orecchia R, Ponti A, Poortmans P, Regitnig P, Rosselli Del Turco M, Rutgers EJ, van Asperen C, Wells CA, Wengström Y, Cataliotti L, EUSOMA (European Society of Breast Cancer Specialists) (2013) The requirements of a specialist Breast Centre. Eur J Cancer 49: $3579-3587$.

This work is published under the standard license to publish agreement. After 12 months the work will become freely available and the license terms will switch to a Creative Commons AttributionNonCommercial-Share Alike 4.0 Unported License. 